\title{
Preparation, Characterization and Evaluation of Efficacy of Phosphorus and Potassium Incorporated Nano Fertilizer
}

\author{
Anjuman Ara Rajonee1, Shurovi Zaman², Shah Muhammad Imamul Huq ${ }^{3}$ \\ ${ }^{1}$ Department of Soil and Environmental Sciences, University of Barisal, Barisal, Bangladesh \\ ${ }^{2}$ Department of Environmental Science and Disaster Management, Noakhali Science and Technology University, Sonapur, \\ Bangladesh \\ ${ }^{3}$ Department of Soil, Water and Environment, University of Dhaka, Dhaka, Bangladesh \\ Email: rajonee.du101361@gmail.com
}

How to cite this paper: Rajonee, A.A. Zaman, S. and Huq, S.M.I. (2017) Preparation, Characterization and Evaluation of Efficacy of Phosphorus and Potassium Incorporated Nano Fertilizer. Advances in Nanoparticles, 6, 62-74.

https://doi.org/10.4236/anp.2017.62006

Received: March 21, 2017

Accepted: May 7, 2017

Published: May 10, 2017

Copyright (c) 2017 by authors and Scientific Research Publishing Inc. This work is licensed under the Creative Commons Attribution International License (CC BY 4.0).

http://creativecommons.org/licenses/by/4.0/

\begin{abstract}
Phosphorus and Potassium incorporated nano fertilizer were prepared using zeolite as a carrier material at a laboratory scale. X-ray diffraction (XRD) analysis was done for the characterization and confirmation of the incorporation. Chemical analyses also indicate the sorption of fertilizer material into zeolite. An in vitro incubation study was conducted for 30 days at field moisture condition to see the release of the fertilizer materials and was compared with a conventional fertilizer. The release pattern of nutrients from either source showed a substantial decreasing trend with time although the release of $\mathrm{P}$ and $\mathrm{K}$ was higher for nano fertilizer than the conventional one. A pot culture experiment with Ipomoea aquatica (Kalmi) was also conducted to see the efficacy of the nano fertilizer in the growth promotion of the plant. Analysis showed higher accumulation of $\mathrm{P}$ and $\mathrm{K}$ in plants grown with nano fertilizer. Post-effect of nano fertilizer application in soil showed better $\mathrm{pH}$, moisture, $\mathrm{CEC}$, available $\mathrm{P}$ and $\mathrm{K}$ under nano fertilizer treatment than the conventional fertilizer.
\end{abstract}

\section{Keywords}

Nano Fertilizer, Preparation, Efficacy, P-Efficiency, K-Efficiency

\section{Introduction}

Modern agriculture depends mostly on inorganic fertilizers, a greater portion of which is readily removed from soil after harvesting. Nowadays growers are striving to overcome the nutrient deficiency and approach the genetic limit of plants [1]. Resorting to replace these nutrients is the ultimate choice [2]. 
Because of agricultural development, different parts of the world have evidences that fertilizer application is the most efficient measure for increasing crop production, sustainable yield growth and food security [3] [4]. Fertilization increases crop yields at a rate of $30 \%$ to $50 \%$, globally [5]. About $40 \%-70 \%$ of the nitrogen and $80 \%-90 \%$ of the phosphorus of the applied fertilizers either are lost into the environment or become unavailable for crops. It not only causes major economic and resource loss but also is responsible for serious environmental pollution [6].

To overcome the problem of fertilizer use and increase economical use, lots of approaches have been made. Among them: application of adequate amount of fertilizer(s); deep placement of fertilizer(s); use of granular urea; improving crop response knowledge [7] and use of slow release nano fertilizer [8] are notable.

Nano fertilizer, the most important field of agriculture, has drawn the attention of the soil scientists as well as the environmentalists due to its capability to increase yield, improve soil fertility, reduce pollution and make a favorable environment for microorganisms [8]. According to the present study, the rate of release of nutrients from laboratory synthesized nano fertilizer and its effects on crop production have been compared with ordinary chemical fertilizer.

\section{Materials and Methods}

The experiment was divided into four parts: synthesis of nano fertilizer in the laboratory, physical and chemical characterization of the product, release pattern of the synthesized nano fertilizer in soil and, pot experiment with plants. Commercially available zeolite (AnalaR, BDH) was used as the carrier material. Synthesis of nano fertilizers was accomplished in two steps previously described [2].

In case of in vitro incubation and macrocosm study, soil samples were collected from an agricultural field near the laboratory following the sample collecting procedures as described in [9]. The geo- location of the sampling site is $23^{\circ} 53.147 \mathrm{~N}$ and $90^{\circ} 24.809 \mathrm{E}$. The processing and preservation of the soil samples were done according to [10].

A leafy vegetables commonly known as Kankong (Ipomoea aquatica) was used for pot culture experiment. Control, conventional fertilizers and the synthesized nano-fertilizer were the treatments. For conventional fertilizer TSP and MOP were used. The amounts of each nutrient from either source were kept at the same level.

Around $2 \mathrm{~kg}$ sizes pots were used. The fertilizer requirement was assessed following Fertilizer Recommendation Guide of BARC [11]. The soils in each pot were mixed with the required amounts of fertilizer except for control. The pots were arranged in a completely randomized design and were set in a net house.

Kangkong seeds (6-7) were sown in each of the pots and allowed to germinate. After germination, 4 seedlings were kept in each pot. Plants were watered every day. Watering was done by using tap water; intercultural operations were carried out whenever it was necessary.

The plants were harvested carefully by uprooting them after 30 days of emer- 
gence. Processing and preparation of the plant samples were done as in [12].

Various physical, chemical and physico-chemical properties of the soil samples were analyzed as in [10]. After harvesting, the soils were again analyzed to monitor the effect of nano fertilizer on soil after a period of time.

In-vitro incubation study was done to observe the release characteristics of the elements from the synthesized nano fertilizer using the same categories of soil. $250 \mathrm{gm}$ of $5 \mathrm{~mm}$ sieved soil was used for the study. The procedure followed is similar to what has been described in [13]. The period of incubation was 0,15 and 30 days. Analytical procedures followed were as described earlier.

All data were statistically analyzed by using Microsoft Excel and MINITAB (version 17) packages.

\section{Results and Discussions}

\subsection{Preparation and Characterization of Nano Fertilizer}

The collected zeolite was analyzed in the laboratory before the synthesis of nano fertilizer. Some properties of the zeolite were again measured after surfactant modification. The changes in organic carbon percentage (from $0.084 \%$ to $0.21 \%$ ) and CEC (from $35.71 \mathrm{meq} \%$ to $48.57 \mathrm{meq} \%$ ) confirmed the modification. The $\mathrm{P}$ and $\mathrm{K}$ content of the zeolite were very low initially but rose to a higher level after the synthesis of the nano fertilizers. These are the indication of successful incorporation of the fertilizer elements onto the modified zeolite (Table 1).

Table 1. Some chemical properties of Zeolite and the Synthesized nano Fertilizer.

\begin{tabular}{ccc}
\hline Properties & Zeolite & Synthesized Nano Fertilizer \\
Total Phosphorous (\%) & 0.26 & 3.60 \\
Available Phosphorous (\%) & 0.03 & 0.47 \\
Total Potassium (me/100g) & 32.14 & 196.68 \\
Available Potassium (me/100g) & 0.02 & 138.20 \\
\hline
\end{tabular}

The X-Ray diffraction (XRD; $\mathrm{Cu} \mathrm{Ka}$ as the source for X-rays) analysis of Zeolite, surfactant modified zeolite, $\mathrm{P}$ and $\mathrm{K}$ incorporated nano fertilizers were done for final confirmation. The d-spacing values of different samples gave the confirmation. The results of XRD are given in Figures 1(a)-(d).

The XRD analysis of surfactant modified zeolite showed changes in position and height of the peak compared to the unmodified zeolite (Figure 1(a) and Figure 1(b)). The d-spacing values of the prominent peaks are: $12.27 \pm 0.01$, 8.68, 4.10, $3.70 \pm 0.01,3.28,2.98,2.75,2.68$ and $2.62 \AA$.

Comparing the surfactant modified zeolite with the $\mathrm{P}$ and $\mathrm{K}$ incorporated zeolite it has been observed that the position and height of peak has changed in latter. The peak height showed a decrease for phosphorus (Figure 1(b) and Figure 1 (c)). The d-spacing values of the prominent peaks are as followed $12.28 \pm 0.15$, $8.68 \pm 1.26,4.10,3.70,3.28,2.98,2.75 \pm 0.01,2.68$ and $2.62 \AA$. On the other hand, for $\mathrm{K}$ incorporated zeolite the changes in position and height of peaks are 


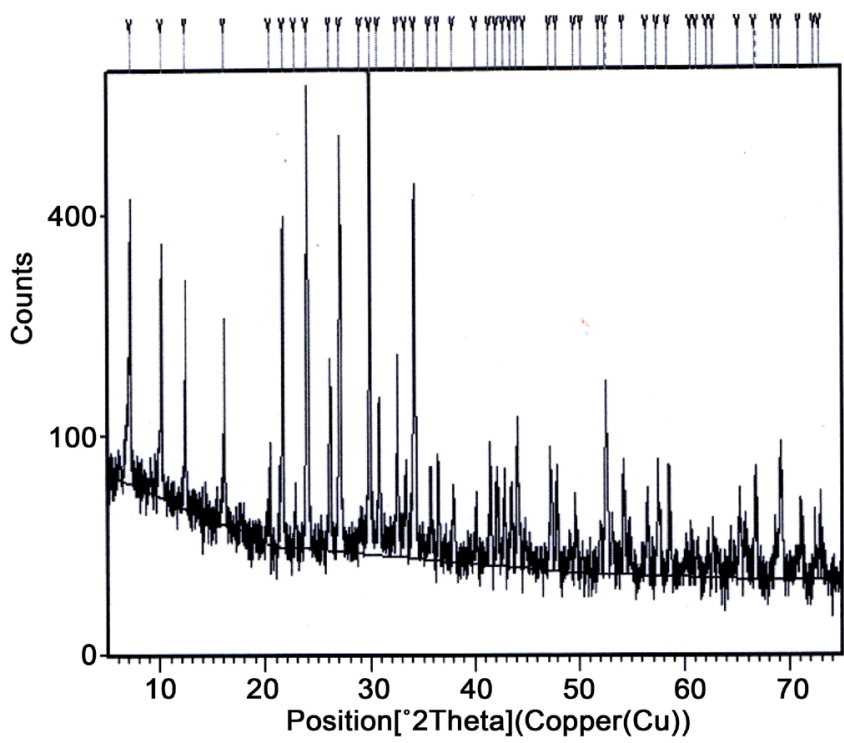

(a)

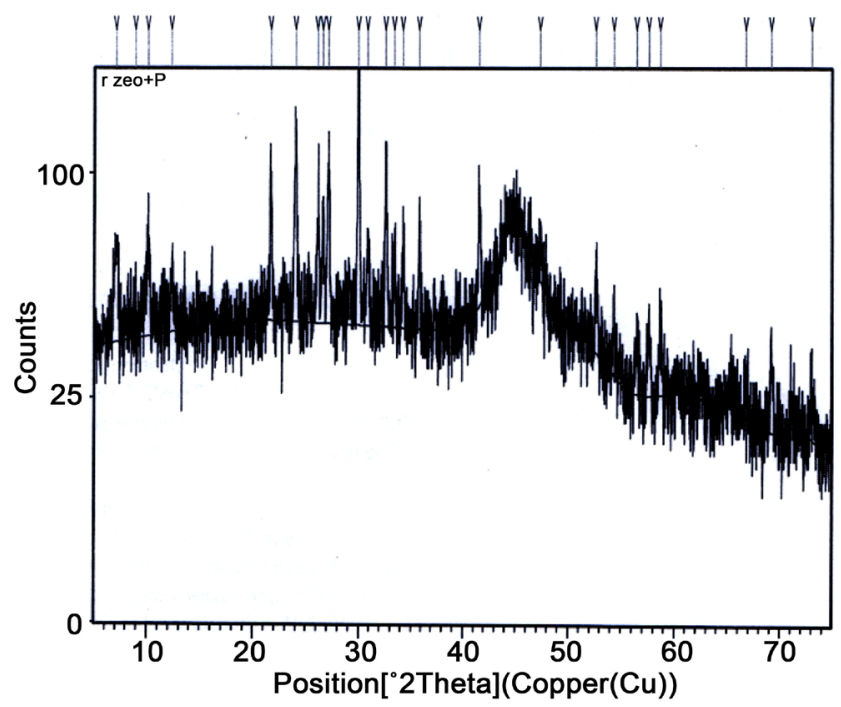

(c)



(b)

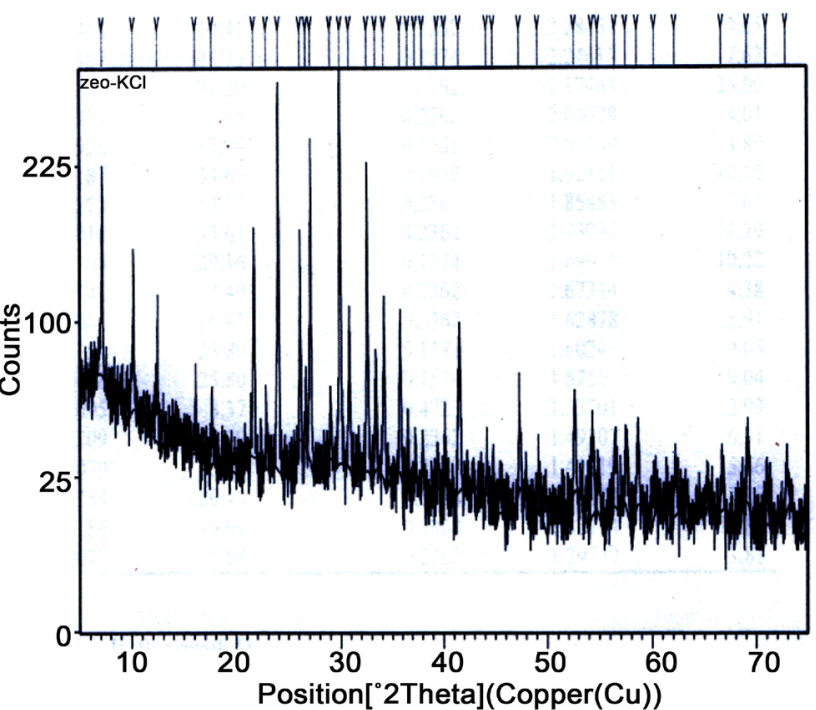

(d)

Figure 1. XRD of the subsequent materials (a) natural Zeolite and (b) surfactant modified Zeolite (c) Zeolite Incorporated with $\mathrm{KH}_{2} \mathrm{PO}_{4}$ and (d) Zeolite Incorporated with $\mathrm{KCl}$.

erratic (Figure 1(b) and Figure 1(d)). The d-spacing values of the prominent peaks are as followed $12.28 \pm 0.05,8.68 \pm 0.02,4.10 \pm 0.01,3.28,2.98,2.75,2.68$ and $2.62 \AA$. Closely matched d-spacing values of all of these zeolites are suggestive of a containment of the zeolite structure whereas the varied peak height is indicatives of positive modification [14].

\subsection{Initial Characteristics of Soil}

Some common physical, chemical and physicochemical properties of the soil were analyzed before the experimental setup in order to know the initial nutrient status of the soil. The experimental soil was silty clay in texture, acidic in reaction ( $\mathrm{pH}$ 5.92). The soil contained $1.58 \%$ organic matter, total organic carbon $0.92 \%$, total N $0.1 \%$, total P $0.07 \%$, total K 125.85 meq\%, total S 3.18\%, available 
N $0.002 \%$, available P $0.001 \%$, available K 0.19 meq\%, available S $0.0007 \%$ and CEC $5.79 \mathrm{meq} \%$. The moisture content of the soil was $22.54 \%$.

\subsection{In-Vitro Incubation Study}

\subsubsection{Soil pH}

The $\mathrm{pH}$ decreased for any day of sampling (0,15 and 30). The initial $\mathrm{pH}$ of the conventional fertilizer and nano fertilizer treated soil was higher than the control soil. On the following days, $\mathrm{pH}$ of all soils regardless of their treatments decreased. However, the decrease was slow in the final phase of the experiment. In every case, the $\mathrm{pH}$ of nano fertilizer treated soil was greater than the control soil for phosphorus incorporated nano fertilizer (P-nf) and was lower than the control soil except for potassium incorporated nano fertilizer (K-nf) in 0 day (Table 2).

Table 2. $\mathrm{pH}$ of soil at different incubation days after application of nano fertilizer.

\begin{tabular}{ccccc}
\hline & \multicolumn{2}{c}{$\mathrm{pH}$} \\
\cline { 2 - 5 } Incubation Days & Control & Conventional fertilizer & \multicolumn{2}{c}{ Nano fertilizer } \\
\cline { 3 - 5 } & & & $\mathrm{P}-\mathrm{nf}$ & $\mathrm{K}-\mathrm{nf}$ \\
\hline 0 & 4.96 & 5.23 & 5.45 & 5.29 \\
15 & 4.93 & 4.47 & 5.26 & 4.65 \\
30 & 4.56 & 4.39 & 4.93 & 4.45 \\
\hline
\end{tabular}

A higher initial $\mathrm{pH}$ due to the application of nano fertilizer could be related to the alkaline nature of zeolite. The reason for decreasing $\mathrm{pH}$ may be because of maintaining moist condition. Regression analysis was done for the treatments and the slope is steep indicating the fact that the nano fertilizer has non- significant positive effect on soil $\mathrm{pH}$.

\subsubsection{Soil Moisture}

Zeolite is often used as an excellent water moderator and it can absorb up to $55 \%$ of their weight [15] so it is likely that zeolite based nano fertilizer application could improve water-holding capacity of a soil. With this view in mind, moisture percentages in the different treated soils were determined after each incubation period. It is interesting to note that, although similar amount of water was added to each soil for moistening purpose, the nano fertilized soils, however, retained more water compared to control and conventional fertilizer applied soils (Table 3). This is an indication that zeolite based nano fertilizer could also improve the water use efficiency (WUE).

Regression analysis shows that the slope is relatively steeper indicating that the nano fertilizer has a non-significant positive effect on soil moisture.

\subsubsection{Available Phosphorous}

Effects of application of nano fertilizer on available phosphorous in soil are presented in Table 4. The initial $\mathrm{P}$ was the highest in nano fertilizer treated soils while the control soil had the least. However, the release of P was apparently 
Table 3. Moisture content of soil after application of nano fertilizer at different incubation days.

\begin{tabular}{ccccc}
\hline \multirow{2}{*}{$\begin{array}{c}\text { Incubation } \\
\text { Days }\end{array}$} & Control & Conventional fertilizer & \multicolumn{2}{c}{ Nano Fertilizer } \\
\cline { 2 - 5 } & & & P-nf & K-nf \\
\hline 0 & 20.82 & 20.7 & 20.72 & 20.85 \\
15 & 21.56 & 27.58 & 30.49 & 31.2 \\
30 & 13.22 & 23.53 & 25.10 & 25.62 \\
\hline
\end{tabular}

Table 4. Available phosphorous of soil after nano fertilizer applications at different incubation days.

\begin{tabular}{cccc}
\hline & \multicolumn{3}{c}{ Available phosphorous $(\mathrm{mg} / \mathrm{kg})$} \\
\cline { 2 - 4 } Incubation Days & Control & Conventional fertilizer & Nano Fertilizer \\
\cline { 3 - 4 } & 10 & 30 & P-nf \\
\hline 0 & 6 & 8 & 30 \\
30 & 4 & 6 & 20 \\
\hline
\end{tabular}

steeper in case of nano fertilizer than the rest. The release of higher amount of phosphorous by nano fertilizer treated soil may be because of well incorporation of $\mathrm{KH}_{2} \mathrm{PO}_{4}$ onto zeolite as revealed in XRD analysis (Figure $1(\mathrm{c})$ ). The $\mathrm{P}$ supply from nano fertilizer remains available even after a long time compared to conventional fertilizer [14]. Our findings corroborate with this observation. Regression analysis between the treatments shows that the angle of the slope is very steep indicating that the nano fertilizer has a non-significant positive effect on the release of $\mathrm{P}$ in soil.

From, Percent release of phosphorous in conventional fertilizer and nano fertilizer shows that conventional fertilizer has an initial higher rate of release then a sharp decrease continued for the other days of incubation (Figure 2). Conventional (T.S.P) fertilizer gives an indication of exhaustion after 15 days to 30 days of incubation. This may be a sign of fixation at lower $\mathrm{pH}$. But in case of nano

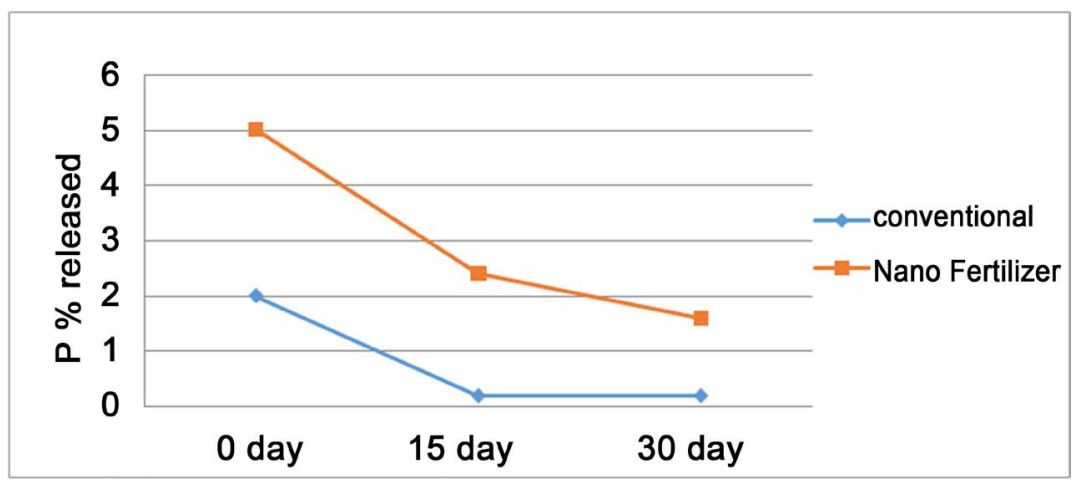

Figure 2. Percent release of phosphorus by conventional and nano fertilizer at different incubation days. 
fertilizer though the trend is similar to that of conventional fertilizer, the rate of release however, was higher even for the last day of incubation. The release did not level off like the conventional fertilizer. This could be an indication of continuous release of $\mathrm{P}$ or a smaller fixation of the nano-P than conventional one.

\subsubsection{Available Potassium}

Effects of application of nano fertilizer on available potassium in soil are presented in Table 5. Throughout the entire experiment, potassium release was prominent in case of nano fertilizer and all the experimental units exhibited the same trend though at different degrees. The control soil contained less $\mathrm{K}$ than the rest. It is interesting to note here that although similar amount of $\mathrm{K}$ was added through both conventional as well as nano fertilizers, yet the zeolite carried $\mathrm{K}$ fertilizer appeared to have released higher quantities of the element under similar conditions. Similar observations were made by [16] mentioned that the $\mathrm{K}$ content in the soils were maintained at high level in the potassium incorporated zeolite than in control treatment.

Table 5. Available potassium of soil after nano fertilizer applications at different incubation days.

\begin{tabular}{cccc}
\hline & \multicolumn{3}{c}{ Available potassium $(\mathrm{me} / 100 \mathrm{~g})$} \\
\cline { 2 - 4 } Incubation Days & Control & Conventional fertilizer & Nano Fertilizer \\
\cline { 3 - 4 } & 0.19 & 1.06 & K-nf \\
\hline 0 & 0.12 & 0.82 & 1.51 \\
30 & 0.09 & 0.48 & 0.70 \\
\hline
\end{tabular}

So, it has a great role to play as a potential slow release fertilizer. Regression analysis done between the treatments shows that the angle of the slope is steep indicating that the nano fertilizer has a non-significant positive effect on the release of $\mathrm{K}$ in soil. From Figure 3 it is observed that percent release of potassium in conventional fertilizer and nano fertilizer shows a decreasing trend but the release is always higher for nano fertilizer throughout the whole incubation period even in the last day of observation. But nano fertilizer shows a quicker decrease from 15 days to 30 days than conventional. The same fertilizer is used as



Figure 3. Percent release of potassium by conventional and nano fertilizer at different incubation days. 
the source of potassium $(\mathrm{KCl})$ but the release is higher for nano fertilizer. The trend of $\mathrm{K}$ release from the synthesized nano fertilizer could be an indication that the bond of $\mathrm{K}$ with the surface modified zeolite has not been strong. This however, needs further study using a different carrier.

\subsection{Macrocosm Study}

\subsubsection{Visual Symptoms}

The germination, growth and visual appearance of the Kalmi plants were observed. It appeared that the growth of Kalmi was equally better in fertilized (conventional or nano) soils than the control. However, between the conventional fertilizer and nano fertilizer treatments, plant performance was better with the nano fertilizers.

No pest and insect infestations were observed on the leaves of Kalmi plants and soil showed firm consistency, better absorption of water and no subsidence or water logging condition. However, control and conventional fertilizer treated soils showed considerable subsidence.

\subsubsection{Fresh and Dry Matter Production of Kalmi}

The growth of Kalmi as affected by the various treatments (on fresh and dry weight basis) is shown in Table 6. It was observed that the fresh weight production of kalmi was higher in nano fertilizer treated soil compared to the soil without any treatment. The fresh and dry weight production on nano fertilizer treated soil was more or less same to that of conventional fertilizer.

Table 6. Fresh and dry weight (g/100 plants) production of Kalmi plant (Ipomoea aquatica).

\begin{tabular}{ccc}
\hline Treatment & Fresh Weight (g/100 plants) & Dry Weight $(\mathrm{g} / 100$ plants $)$ \\
\hline Control & 67.67 & 4.3 \\
Conventional & 75.67 & 5.1 \\
P-nf & 75.67 & 5.1 \\
K-nf & 74.33 & 4.67 \\
\hline
\end{tabular}

An analysis of variance test showed that there is a significant effect of the treatments on the fresh weights and dry weight of Kalmi, $\mathrm{P}$ value is 0.000 in both cases. To test the efficiency LSD (Lest significance difference) was done and it appeared that the LSD of fresh weight and dry weights are 0.09 at $5 \%$ level.

\subsubsection{Phytoavailability of Phosphorous and Potassium in Kalmi}

\section{1) Phytoavailability of Phosphorous}

To assess the phytoavailability of phosphorus in the kalmi plant at different treatments, the concentration and uptake of phosphorus were measured.

The concentration and uptake of phosphorus in Kalmi is presented in Table 7 and from the table it is observed that the nano fertilizer treatments caused an increased phosphorus concentration in the Kalmi plant. Phosphorus concentration was in the minimum for control plant $(800 \mathrm{mg} / \mathrm{kg})$. The concentration of 
Table 7. The concentration and uptake of $\mathrm{P}$ in kalmi plant.

\begin{tabular}{ccc}
\hline & Phosphorous $(\mathrm{P})$ \\
\hline Treatment & Concentration $(\mathrm{mg} / \mathrm{kg})$ & Uptake $(\mathrm{mg} / 100$ plants $)$ \\
\hline Control & 800 & 34.67 \\
Conventional & 830 & 42.33 \\
P-nf & 1900 & 96.90 \\
\hline
\end{tabular}

phosphorus was more or less same in case of control and conventional treatment. Uptake of phosphorus (P) by the Kalmi plants was calculated by multiplying the concentration of phosphorus $(\mathrm{P})$ in the plant with their corresponding dry matter production. It is observed from the analysis that uptake of phosphorus by the Kalmi plants was higher in both of nano fertilizer over control.

ANOVA test indicated that there is a significant effect of the treatments on phosphorus concentration ( $\mathrm{P}$ value 0.00 ) and on the uptake by the plant ( $\mathrm{P}$ value 0.00 ). The LSD of concentration and uptake of $\mathrm{P}$ at $5 \%$ level are 89.86 and 0.09 respectively.

A balance sheet has been prepared to assess the fate of phosphorus in the system and it is presented in Table 8 .

Table 8. Balance sheet of phosphorus (mg/pot) in different experimental pot (only inorganic fraction is considered).

\begin{tabular}{cccc}
\hline & \multicolumn{3}{c}{ Experimental Plot } \\
\cline { 2 - 4 } P (mg/pot) & Control & Conventional & P-nf \\
\hline Initial content in the soil & 10 & 10 & 10 \\
From different fertilizer source & 0.00 & 14 & 14 \\
Total P content in the pot (a) & 10 & 24 & 24 \\
Removed through plant uptake (b) & 0.10 & 0.13 & 0.3 \\
Present in soil after harvest (c) & 11 & 14 & 30 \\
B + c = d & 11.01 & 14.13 & 30.3 \\
Amount missing (a-d) & -1.01 & 9.87 & -6.3 \\
Percent (\%) P not accounted for & -10.1 & 41.13 & -26.3 \\
\hline
\end{tabular}

From Table 8 it is observed that, all the experimental pot initially contained $24 \mathrm{mg} /$ pot of phosphorous except for control (10 mg/pot). Some of this phosphorous is taken up by the Kalmi plants. So, the excess amount of phosphorous is supposed to remain in the soil after harvesting of the crops. The calculated values, however, indicate that the entire $\mathrm{P}$ is not recovered in some cases and in other cases it was more than its application. The maximum percentage of missing phosphorous is 41.13 while the minimum is for phosphorous containing nano fertilizer treated soil $(-26.3 \%)$. The reason could be that in soils treated with phosphorus incorporated nano fertilizer, the phosphorous used by the plants somehow was disturbed and as a result they might have been fixed in low $\mathrm{pH}$ and turned into an unavailable form. Whereas, the phosphorous release and 
uptake is more than its application may be due to later release of phosphorous from soil at higher $\mathrm{pH}$ in control and phosphorous containing nano fertilizer treated soil. The better balance sheet for P-containing nano fertilizer indicates that the nano fertilizer synthesized was efficient. Moreover, one must understand that in this treatment, the source of $\mathrm{P}$ incorporated into nano particle was potassium di hydrogen phosphate while in other pots the source of $\mathrm{P}$ was TSP. Hence, the solubilization process of the added TSP needs to be considered too.

\section{2) Phytoavailability of Potassium}

Potassium $(\mathrm{K})$ concentration and uptake was observed to have a cumulative idea about its accumulation in Kalmi plant due to different nano fertilizer treatments (Table 9).

Table 9. The concentration and uptake of $\mathrm{K}$ in Kalmi plant.

\begin{tabular}{ccc}
\hline & Potassium $(\mathrm{K})$ & \\
\hline Treatment & Concentration $(\mathrm{me} / 100 \mathrm{~g})$ & Uptake $(\mathrm{mg} / 100$ plants $)$ \\
\hline Control & 111.13 & 187.81 \\
Conventional & 115.99 & 230.70 \\
K-nf & 126.31 & 229.88 \\
\hline
\end{tabular}

Concentration of potassium (K) in Kalmi plant is presented in Table 9 and from the table it is observed that the concentration of potassium $(\mathrm{K})$ is highest in $\mathrm{K}$ - nf $(126.31 \mathrm{me} / 100 \mathrm{~g})$ treated soil. The concentration was $115.99 \mathrm{me} / 100 \mathrm{~g}$ in case of conventional fertilizer. Uptake of potassium (K) by the Kalmi plant was calculated by multiplying the concentration of potassium $(\mathrm{K})$ in the plant with their corresponding dry matter production. It is observed from the analysis that potassium uptake was more or less similar in case of conventional and K-nf (Potassium containing nano fertilizer) treated soil but every treatment shows better uptake than control.

An analysis of variance i.e. ANOVA test was done and it appeared that there is a significant effect of the treatments on potassium concentration ( $P$ value 0.00 ) and uptake (P value 0.00$)$ in Kalmi plants. The LSD of concentration and uptake of $\mathrm{K}$ are 0.09 at $5 \%$ level.

A balance sheet has been made to assess the fate of potassium in the system and it is presented in Table 10 .

From Table 10 it is observed that, all the experimental pot initially contained $89.1 \mathrm{mg} /$ pot of potassium except for control $(74.1 \mathrm{mg} / \mathrm{pot})$. The balance sheet indicates that some of this potassium has been taken up by the Kalmi plants but the entire $\mathrm{K}$ is not recovered; some amount is missing in the calculations. The situation is more apparent for control fertilizer $38 \%$ which was the maximum while the minimum is for potassium containing nano fertilizer treated soil $(0.34 \%)$. From the balance sheet it is observed that the nano fertilizer synthesized was efficient. Though same source of potassium were added to the soil, potassium provided by nano fertilizer is utilized for the maximum. It may be due to the better release and uptake of potassium from nano fertilizer than conventional fertilizer indicating the fact that it needs carrier material other than Zeo- 
Table 10. Balance sheet of potassium (mg/pot) in different experimental plot (only inorganic fraction is considered).

\begin{tabular}{cccc}
\hline \multirow{2}{*}{ K (mg/pot) } & \multicolumn{3}{c}{ Experimental Plot } \\
\cline { 2 - 4 } & Control & Conventional & K-nf \\
\hline Initial content in the soil & 74.1 & 74.1 & 74.1 \\
From different fertilizer source & 0.00 & 15 & 15 \\
Total K content in the pot (a) & 74.1 & 89.1 & 89.1 \\
Removed through plant uptake (b) & 5.63 & 6.92 & 6.9 \\
Present in soil after harvest (c) & 40.17 & 66.3 & 81.9 \\
b + c = d & 45.8 & 73.22 & 88.8 \\
Amount missing (a-d) & 28.3 & 15.88 & 0.3 \\
Percent (\%) K not accounted for & 38.19 & 17.82 & 0.34 \\
\hline
\end{tabular}

lite for preparation of potassium containing nano fertilizer.

\subsubsection{After Effects of Nano Fertilizer}

After harvesting the properties of soils were measured and the changes are monitored in Table 11.

Table 11. Changes in properties of soil after harvesting of Kalmi plant.

\begin{tabular}{ccccccc}
\hline Treatment & $\mathrm{pH}$ & $\begin{array}{c}\text { Moisture } \\
(\%)\end{array}$ & $\begin{array}{c}\text { Organic } \\
\text { Carbon } \\
(\%)\end{array}$ & $\begin{array}{c}\text { Available P } \\
(\mathrm{mg} / \mathrm{kg})\end{array}$ & $\begin{array}{c}\text { Available K } \\
(\mathrm{me} / 100 \mathrm{~g})\end{array}$ & $\begin{array}{c}\text { CEC } \\
(\mathrm{me} / 100 \mathrm{~g})\end{array}$ \\
\hline Control & $5.6(5.9)$ & $2.8(4.6)$ & $1.5(0.92)$ & $11(10)$ & $0.10(0.19)$ & $6.14(5.79)$ \\
Conventional & $5.6(5.9)$ & $2.7(4.6)$ & $1.7(0.92)$ & $14(10)$ & $0.17(0.19)$ & $5.93(5.79)$ \\
P-nf & $5.9(5.9)$ & $2.9(4.6)$ & $1.7(0.92)$ & $30(10)$ & $0.18(0.19)$ & $7.36(5.79)$ \\
K-nf & $5.4(5.9)$ & $2.8(4.6)$ & $1.1(0.92)$ & $13(10)$ & $0.21(0.19)$ & $7.07(5.79)$ \\
\hline
\end{tabular}

(The figures in the parentheses indicate the initial values).

By comparing the properties of after harvest soil with initial soil properties (Table 11) it is observed that $\mathrm{pH}$ of the soils decreased slightly except for P-nf. The reason for decreasing $\mathrm{pH}$ may be due to root exudates of plant though it is almost in a good range for agricultural production. Regression analysis $\left(\mathrm{R}^{2}=\right.$ $74.2 \%$ ) shows that the angle of the slope is steep for $\mathrm{pH}$ indicating that the nano fertilizer has a non-significant positive effect on $\mathrm{pH}$.

The moisture content of the soils has also decreased comparing with initial. It may be due to uptake of moisture by plants or by evapotranspiration loss. The Regression analysis $\left(\mathrm{R}^{2}=68.2 \%\right)$ shows that the angle of the slope is steep indicating that the nano fertilizer has a non-significant positive effect on soil moisture.

In case of Organic Carbon, treatment shows better percentage than control comparing with initial. Regression analysis $\left(\mathrm{R}^{2}=18.1 \%\right)$ shows that the angle of the slope is slightly steep indicating that the nano fertilizer has a non-significant positive impact on OC. 
Zeolites have a high cation exchange capacity and often used as inexpensive cation exchanger [17] [18]. It may be the reason of increasing CEC of soils which is treated with nano fertilizer than the other. Regression analysis $\left(\mathrm{R}^{2}=54.9 \%\right)$ shows that the angle of the slope is steep indicating that the nano fertilizer has a non-significant positive effect on CEC.

The available phosphorous content of the after harvest soil are much higher than their respective initial values except for control soil. Available phosphorous is much higher in P-nf (phosphorus containing nano fertilizer) treatment than the others. This may because of left-over fertilizer in soil and nano fertilizer holds higher amount of inorganic phosphorous than conventional one. Regression analysis $\left(\mathrm{R}^{2}=98.3 \%\right)$ shows that the angle of the slope is very steep indicating that the nano fertilizer has significant positive effect on available phosphorous. The case is also similar for available potassium content. Potassium containing nano fertilizer (K-nf) treated soil contains much higher available potassium than the others. Regression analysis $\left(\mathrm{R}^{2}=7.1 \%\right)$ shows that the angle of the slope is slightly steep indicating that the nano fertilizer has a non-significant positive effect on available potassium.

\section{Conclusion}

The growth of Kalmi, its uptake and concentration of phosphorus $(\mathrm{P})$ and potassium $(\mathrm{K})$ were better in nano fertilizer treatments than in the conventional fertilizer treatments indicating the fact that there is a bright possibility of nano-fertilizer in agriculture. Using this in the farmers' level, however, will need pilot scale synthesis of the fertilizer. Assessment of cost-effectiveness is a matter of concern. In case of Potassium containing nano fertilizer, further experiment can be done using different carrier.

\section{References}

[1] Tisdale, S.L., Nelson, W.L. and Beaton, J.D. (1990) Soil Fertility and Fertilizer. 4th Edition, Macmillan Publishing Company, New York.

[2] Rajonee, A.A., Nigar, F., Ahmed, S. and Imamul Huq, S.M. (2016) Synthesis of Nitrogen Nano Fertilizer and Its Efficacy. Canadian Journal of Pure and Applied Sciences, 10, 3913-3919.

[3] Bockman, O.C., Kaarstad, O., Lie, O.H. and Richards, I. (1990) Agriculture and Fertilizers. Agricultural Group, Norsh Hydro, Oslo.

[4] Larson, B.A. and Frisvold, G.B. (1996) Fertilizers to Support Agricultural Development in Sub-Saharan Africa: What Is Needed and Why? Food Policy, 21, 509-525.

[5] Stewart, W.M., Dibb, D.W., Johnston, A.E. and Smyth, T.J. (2005) The Contribution of Commercial Fertilizer Nutrients to Food Production. Agronomy Journal, 97, 1-6. https://doi.org/10.2134/agronj2005.0001

[6] Guo, M., Liu, M., Hu, Z., Zhan, F. and Wu, L. (2005) Preparation and Properties of a Slow Release NP Compound Fertilizer with Superabsorbent and Moisture Preservation. Journal of Applied Polymer Science, 96, 2132-2138. https://doi.org/10.1002/app.21140

[7] Brady, N.C. and Weil, R.R. (2005) The Nature and Properties of Soils. 13th Edition, Pearson Education Inc., Upper Saddle River, NJ. 
[8] Ahmed, S., Niger, F., Kabir, M.H., Chakrabarti, G., Nur, H.P. and Imamul Huq, S.M. (2012) Development of Slow Release Nano Fertilizer. Proceedings of the International Workshop on Nanotechnology, Dhaka, Bangladesh.

[9] USDA (1951) Soil Survey Manual. Handbook, 18, 205.

[10] Imamul Huq, S.M. and Alam, M.D. (2005) A Handbook on Analyses of Soil, Plant and Water. BACER-DU, University of Dhaka, Bangladesh.

[11] BARC (2012) Fertilizer Recommendation Guide. BARC Soils Publication No. 45, Dhaka, Bangladesh.

[12] Roy, S., Parveen, Z. and Imamul Huq, S.M. (2012) Effect of Arsenic on the Nutrient Uptake Pattern of Amaranthus. Dhaka University Journal of Biological Sciences, 21, 87-96. https://doi.org/10.3329/dujbs.v21i1.9748

[13] Chowdhury, M.T.A., Nesa, L., Kashem, M.A. and Imamul Huq, S.M. (2010) Assessment of the Phytoavailability of $\mathrm{Cd}, \mathrm{Pb}$ and $\mathrm{Zn}$ Using Various Extraction Procedures. Pedologist, 53, 80-95.

[14] Banishwal, A.K., Rayalu, S.S., Labhasetwar, N.K., Juwarkar, A.A. and Devotta, S. (2006) Surfactant-Modified Zeolite as a Slow Release Fertilizer for Phosphorus. Journal of Agricultural and Food Chemistry, 54, 4773-4779. https://doi.org/10.1021/jf060034b

[15] Pisey, H., Yazid, B. and Semuel, P.S. (2011) Development of Granular Urea-Zeolite Slow Release Fertilizer Using Inclined Pan Granulator. Journal of Teknik Kimia Indonesia, 10, 102-111.

[16] Li, J., Wee, C. and Sohn, B. (2013) Effect of Ammonium- and Potassium-Loaded Zeolite on Kale (Brassica alboglabra) Growth and Soil Property. American Journal of Plant Sciences, 4, 1976. https://doi.org/10.4236/ajps.2013.410245

[17] Millán, G., Agosto, F. and Vázquez, M. (2008) Use of Clinoptilolite as a Carrier for Nitrogen Fertilizers in Soils of the Pampean Regions of Argentina. Ciencia e Investigación Agraria, 35, 293-302. https://doi.org/10.4067/S0718-16202008000300007

[18] Breck, D.W. (1974) Zeolite Molecular Sieves: Structure, Chemistry and Use. John Wiley and Sons, London.

Submit or recommend next manuscript to SCIRP and we will provide best service for you:

Accepting pre-submission inquiries through Email, Facebook, LinkedIn, Twitter, etc. A wide selection of journals (inclusive of 9 subjects, more than 200 journals)

Providing 24-hour high-quality service

User-friendly online submission system

Fair and swift peer-review system

Efficient typesetting and proofreading procedure

Display of the result of downloads and visits, as well as the number of cited articles

Maximum dissemination of your research work

Submit your manuscript at: http://papersubmission.scirp.org/

Or contact anp@scirp.org 